\title{
Barriers Influencing Implementation of Plastic Recycling Process: A Case of Dire Dawa City, Ethiopia
}

\author{
Getu Girma \\ School of Mechanical and Industrial Engineering, Dire Dawa Institute of Technology, Dire Dawa University, \\ Dire Dawa, Ethiopia \\ Kassu Jilcha \\ School of Mechanical and Industrial Engineering, Addis Ababa Institute of Technology, Addis Ababa \\ University, Addis Ababa, Ethiopia
}

\begin{abstract}
Background: In current situation, problems related to municipal solid waste management is much vital and it is necessary to develop habits of recycling. It is better to commercialize for developing sustainable development of municipal solid waste management system. Level of waste and pollution is increasing due to advanced technology, an increasing number of people and a high expansion rate of modernization.Purpose: Therefore, the purpose of this study is to identify the most influential barriers that affect the implementation of the plastic recycling system in Dire Dawa city. Research Approach: The research was conducted based on the evaluation and reviewing of some literatures related to the topic on the back flow of materials from end-users to upper streams. Empirical research was also conducted. The questionnaires were designed on 13 imperative obstacles for the backward movement has been acknowledged. This can be later developed and discussed through the model called MICMAC investigation and carried out subsequently. Finding: This research analysis shows that, around 3,585, 893.5 plastic bottles/week has been collected for recycling and the city has obtained an economic advantage of around $\$ 160,297.824$ monthly. To attain this economic advantage, top management plays a great role followed by the creation of awareness regarding this area as an interpretive structural model (ISM) result has showed. Originality/Value: this work is one of the few and pioneering efforts to investigate ISM practices that used to identify the most barriers affecting the recycling system of plastic material in the Dire Dawa city. Conclusion: This research forward suggestions that can help to solve the process, problems and ensure an effective recovery system, to achieve economic advantage and protect the environment from the adverse effects caused by solid waste thrown here and there in the city.
\end{abstract}

Keywords: Interpretive Structural Model, Municipal Solid Waste, Reachability matrix, Recycling, Structural selfinteraction matrix

DOI: $10.7176 /$ IEL/10-3-01

Publication date: November $30^{\text {th }} 2020$

\section{Introduction}

Municipal solid wastes are increasing due to commercial expansion, technological advances, population growth rates and other associated. Even, the standard life of the people's cases also many complications of increasing solid wastes. It was associated with enhancing the prolonged feeding besides reduction in assets through rapidly increasing the number of the output of municipal types of solid waste is more serious to the current situation.

Therefore, the capacity of converting used products in the recycling process is the most vital one in the manufacturing process for taking a contributing to the value added process. These activities were the most critical ones in today's recycling activities across the world in any manufacturing sector. So, the implementation of certain mechanisms such as reworking, re-engineering, recovery of products, re-used and all this process or application takes a great role in inefficient processes in reverse logistics (RL) systems through the whole supply chain management process. Studies ratified that logistics process has taken the concept of supply chain management to a whole new level (Khan, 2017).

Some Mega project completion in the world through transferring knowledge and technologies, supply chain management (SCM) play a vital role. In today's technological advance, SCM plays a great role in the manufacturing and supply chain system (Chatha, 2015). Most firms deal with ambiguity level of waste management however, it is not considered in behaviors of technical effects. Some study indicated that it was usual that waste can increase due to company's return of the products, product recall for their end life of the product and absent of collecting end life of the products in the global industries (Chakraborty, 2018).

According to both reviewers, Chatha (2015) and Chakraborty (2018) the term reverse logistic(RL) stands for all operations from the upper stream to lower stream is related to end-user of the products, extra portfolio for goods, collection of certain products, product disassembling and flow of resources from upper boundary to the lower boundary of the system. The term RL is also defined as some author argues that it was procedure for preparing, monitoring flow of activities, and organizing process in the inventory in the form of feeding goods from the side 
of feasting to the point of ingesting for the aim of value addition process and to the point of disposal (Chatha, 2015). The most popular definition of the term reverse logistics was defined by many gurus of the management profession during 1990 (Henry, 2016).

According to the definition and reviews of the Henry (2016) the character of Reverse back into the system in most cases such as returns of production, reduction at the source, resources reprocess, reusing and spare, removal of the waste should be included under the definition of the term RL. It is noticed that RL is the one that helps the waste management systems as it add value through its process. The waste that is released from the society can affect the health and safety of dwelling citizen in the area. For that matter this study that was inducted by Henry indicates that $\mathrm{RL}$ is one of the important issues. In most progressive nations and industries, reverse logistic can be recognized viable in a good manner for resource recovering from solid waste of plastics (Govindan, 2016). Even though many countries tried to implement Revers Logistic, especially on the area of solid municipal waste, the usage of the reverse logistic principle is very scrawny.

This study has focused its scope on Diredawa City which is Ethiopian second Federal town in Eastern Ethiopia. In Ethiopia, Dire Dawa city is the most dynamic town with having a tactical topographical region is found between Djibouti and Addis Ababa. Diredaw is the nearest to the port, it used as shipments portion and fatal for exporting and importing of goods and facilities. The most dynamic city in the country with its strategic geographic location between Addis Ababa and Djibouti is serving as transit and terminal for import and export of commodities and servicesThis study is conducted in the city municipality to understand the usage of solid waste management system especially plastic by products. The case study city which is located in Dire Dawa city did not implement the reverse logistic principle to control the city solid wastes. This happened due to the weak management system that is noticed in the city. So, most of the city administrative managements are not working integrated with benchmark cities or areas those help in sharing experience to the improvement of the city waste management system. Due to these cases, solid waste plastic in the city cannot be managed and it can be disposed of here and there in plastic waste containers is neither collected properly nor disposed of in an appropriate manner. These types of waste management are a challenge to avoid its negative impacts on the environment and public health. Therefore, this study is to identify the most influential barriers that affect the implementation of the plastic recycling system in Dire Dawa city. The remaining section of this study is composed of literature review, research methodology, result, discussion and conclusion respectively.

\section{Literature Review}

\subsection{Over view of municipal solid waste}

Municipal Solid waste management systems, especially on plastic waste, in developing countries, are some distance ahead in phrases of methods and tactics deployed, in contrast to prevailing conditions in growing international locations (Kokkinaki, 2017). Studies have put that solid waste management continues to be one of the most overlooked areas of urban improvement and this has known us for sustainable ability of administration (Chwen, 2018). The process is characterized through a wide variety of waste kinds and of these are plastic stable wastes. The genuine fee of waste is not truly the fee of discarded substances. But the process may also include some inefficient use of the material, even pointless use of the strength and liquid such as water inaccurate merchandise. Hence, such weakness of solid waste management system increased the cost of waste management for companies. Cost of waste management is estimated typically $4-5 \%$ of turnover, and can be as high as $10 \%$ of cost coming due to all these cases (Mandal, 2015). According to some studies intends waste administration has grown to be a complicated area, legally, technically and commercially. Very few administrations can rely on the waste collection services furnished through neighborhood, authorities as an entire reply to their waste management obligations. Even they can deiced to obligate companies to back and minimizing the number of waste dumping here and there in the market. According to Quartey et al, (2015) study directed in Ghana that is as of late, utilized and discarded strong plastic by shoppers through waste administration exercises was made through natural issues. In addition to these, it fortifies the thought of an inefficient society. Ultimately, the awareness of this issue prompted expanding pressure from general society for useful and productive measures to illuminate the test of the waste issue in the nation (Quartey et al., 2015). As certain surveys show that the countryside of strong waste management system in urban areas of creating nations like Nigeria is a significant social or natural test (Clive et al, 2016).

In study it is shown that municipal waste quantities were directly or indirectly linked with economic activities, economic development and resource consumption. Currently, economic development in Ethiopian countries has driven urban growth, which is approximately 8\%-10\% per year (Kebede, 2015). In Ethiopia especially in Dire Dawa city the rate of waste generation is relatively very high. This is as a result of industrialization, consumer behavior, economic development, and a wealthy urban population (Heng, 2018). According to Ethiopian Pollution Control Department report (PCD), total amount of municipal solid waste generated per day in the nation increasing from the total amount of solid waste generated per day in the nation grew from unevenly 25,300 tons in 2013 to 39,850 tons in 2018 which shows the increasing rate per each year (Salomon, 2018). 


\subsection{Barriers affecting implementation of reverse logistic system}

The concept of the term reverse logistic system gained attention in the most recent decades, because of various variables (Ravie, 2018). Despite the fact that practices related to reverse logistics have helped the cause of environmental protection, practicing the much-needed approaches is not free from barriers. In spite of the way that practices identified with reverse logistics have helped the reason for environmental protection, it is needed practicing the genuinely necessary methodologies isn't liberated from the Barriers (Lambert, 2015). Competitiveness and showcasing thought processes, direct financial intentions and worries with the earth are a portion of the most significant of them. With the authoritative estimates straightening out, there are very few choices left to the organizations or with manufacturing companies (Shue, 2015). But still to go to reverse logistic system, there were many obstacles. The execution of these might be a hazardous undertaking for the top administration as it includes money related and operational angles, which decide the presentation of the organization over the long haul (Mandal, 2017). A basic investigation of the Barriers hindering reverse logistics and their interaction with the different perspectives in integrative arranging can be a significant wellspring of information to decision makers (Stock, 2016). Studies show that reverse logistic utilization is a very important methodology.

\subsection{Product recovery network perspective}

According to Fleischmann et al. (2018) assessments, item recuperation systems ordered dependent on their principle contrasts following the level of centralization, number of levels and connections with different systems. For the most part it tends to be isolated into three sorts. Those are: (1) reusing systems; (2) amassed item remanufacturing systems; and (3) reusable systems. According to Salomon (2019) reviews, product recovery or disposable options into the following eight types. Those are product repair, reuse, or resale, refurbishing, remanufacturing, cannibalization, recycling, incineration and disposal in landfills at the end. Each of this recovery system involves collection followed by a combination of selection or inspection which carried out through the sorting process based on the types, after that reprocessing or recovering process takes place and finally, redistribution of the activities (Chudhury, 2017). Reverse channel members may perform a different set of logistical functions, including collection from the consumer, sorting, storage, transport, compaction or densification and communication or intermediate processing of recyclables into a usable form. Backward flow or reverse flow of used product is characterized under uncertain paths, and reverse logistic channels might take several forms depending on waste volume, size, and distance from markets, stakeholders and their experience (Pohlen, 2019).The significant impacts influencing waste administration were classified into six zones: socialcultural, technical, economical related, hierarchical, and legitimate political hindrances and population growth (Rochma, 2015). Therefore, the studies had tried to indicate the mechanisms that help the waste management system. The recycling, reuse, repair, rework and dispositions are mentioned some of the method to use solid waste for the second time.

\subsection{Economic perspective}

Developing and implementing successful recycling system is one of the important works of the local government. Giving awareness for the community in order to consider the value of waste and developing habits of thinking before throwing thing is away significantly reducing waste volume (yukalang, 2017). Various financial systems impact the suitability of reusing plastics. According to the study conducted by Mwanza (2018), the impact of a waste administration strategy is when the predictable administration of burn through materials occurs over some undefined time frame. Benefitting from squander is a financial driver that impacts squander authorities and foragers to reuse squander. According to the study made by Sumalee and Vilas (2014) showed that Economic growth in developing countries accelerated waste generation and Thailand also is experiencing issues related to increase waste generation and improper waste management. This study also indicated that in their result the country's domestic waste utilization is only $20 \%-26 \%$ of the waste generated. Another study put that fitting MSWM will presumably bring about diminishing neediness, diminishing baby mortality, improving maternal, and forestalling illness, which are MDG wants one, four, five, and six, individually (Deshmukh, 2016). Today, as worldwide extensive creation of waste material was upgrading gradually in the globe to make progress toward a dressed greatness of life expectancy of the item. Indeed, even it was conceivable to build up a few components in the method of the amount of waste material going into landfill and again limiting or then again decreasing, for instance, igniting with essentialness age and recovery over reprocessing that all can be around contemplated the strategies in what manner can legitimate for overseeing metropolitan strong waste (Ravi, 2015).

\subsection{Technological strategies perspective}

Recently, due to technological advance the cost of recycling has decreased as a result of its advance and subsequently closing the recycled plastic value and the gap between virgin plastics (Zhang, 2014). As a result of advancements in wasting and sorting technologies, non-bottle packing recycling has become possible in Europeans 
countries such as Spain, Austria, Italy, Norway and Germany (Hopwell). Further, compared to other waste types, a greater number of different technologies are required to recycle plastics and therefore the development of new technologies for recycling plastics should be on the agenda of reckless [Hasan 2014]. The strategy that utilizes advanced technology will bring eminent change in solid waste management system of cities and increasing the health and safety of the citizen.

In general, it is found that many studies have tried to put solid waste management from the cities are not well handled in developing countries. Especially Ethiopia is the prone country to these waste management system. The mechanisms of waste management in the cities are being underprivileged as shown in many studies of developing countries. The city administrations are very feeble in decision making and need to follow the latest technologies and philosophies to manage and control solid wastes of the city. This mechanism will increase the society health and safety thereby increase productivity of the country.

\section{Research Methodology}

3.1. Study area and Scope

It is more about the barriers that hinder reverse logistic system in the Dire Dawa City, using the interpretive structural model (ISM) that indicates the interrelationships of the problems and their levels. These barriers are additionally relying on their using potentials and dependence. This may base on the evaluating and reviewing of some literatures on the backflow of materials from end-users to upper stream or back revers logistic systems. Especially depending on the bottling company, Dire Dawa City Administration and Dire Dawa sanitation, 13 the most imperative obstacles to backward movement can be acknowledged. This can be later utilized in the event for the progress of the model, which is further, developed and discussed through the model called MICMAC investigation and carried out subsequently.

\subsection{Model development using ISM procedure}

An interpretive structural model which is further analyzed through the MICMAC procedure is used embraced into making the right decision here to identify most barriers that affecting reverse logistics in the Dire Dawa City today. This procedure needs somehow skill of computing for identifying and developed certain relationships between each individual barrier that affecting the implementation of the system in the selected case. The most core ideas of this system is to crumble the complex structure to numerous structures using certain opinions of the customers, factory experts and other experienced. The system can be used to identify the most influential barriers and analyzing their relationships between definite barriers that may be defined as complexity (Lambert, 2018). According to (Henry and Stock, 2016) reviews, ISM methodology is used to examine such imperative dealer variety standards which used to identify their relationship, their levels and selection criteria. Furthermore, the dependence and power of the system may categorize. The followings are steps in developing ISM procedure that resulted in Figure 1 model developments. 


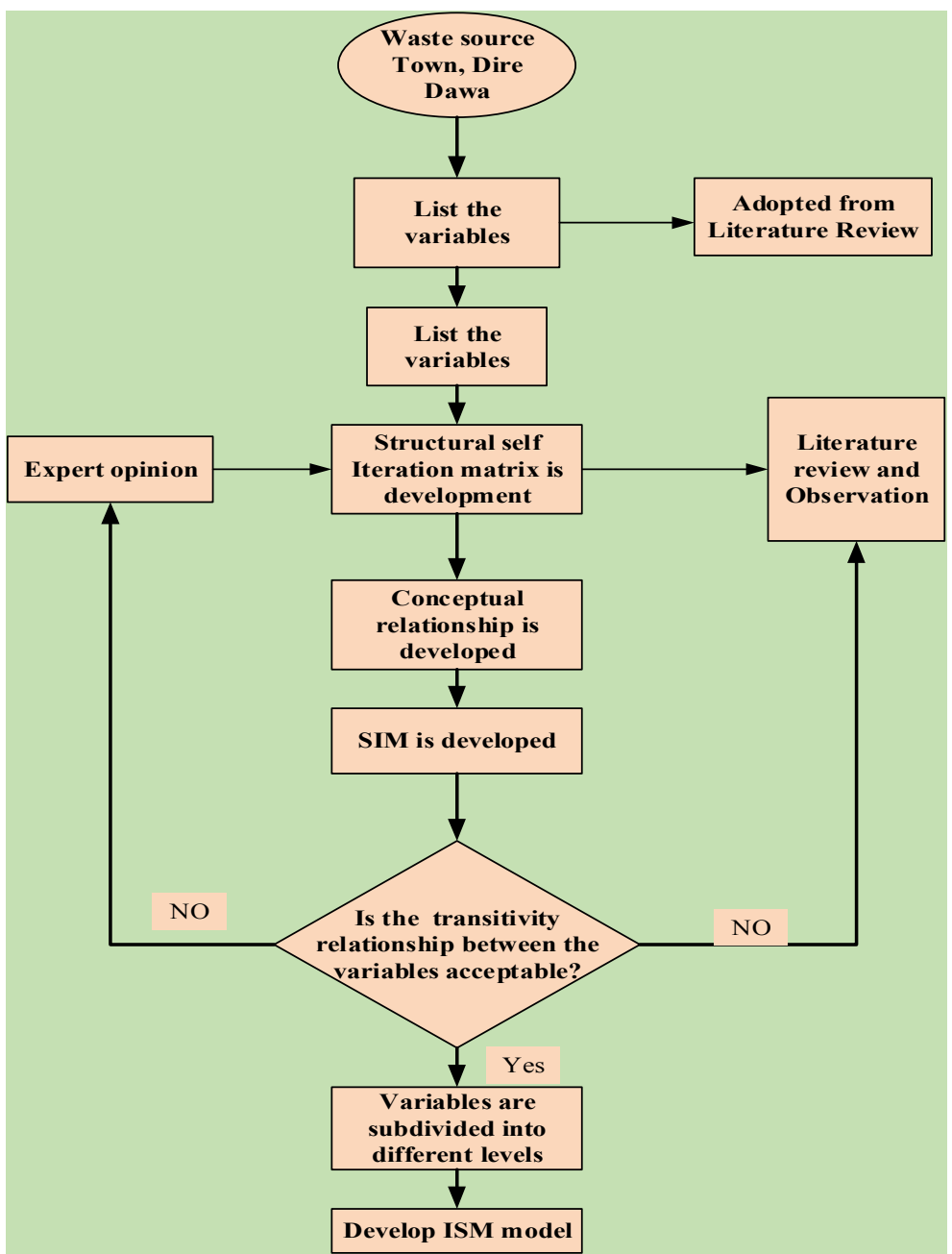

Figure 1: Model developed for ISM [Source; - own]

Step 1: - list all barriers that disturbing reverse logistic scheme

Step 2: - From variable listed in step 1 above, develop a relative link between each other

Step 3: -To develop the interaction matrix between the variables which shows pairwise interactions between the barriers.

Step 4: -the relationship between the matrixes Reachability matrixes obtained would be for the system in to tested affiliation of the system.

Step 5: -the relationship matrixes that achieved at stage 4 would be is subdivided into certain stages.

Step 6: - followed the above stages and an indirect graph has been drawn and the other variables were removed.

Step 7:- result from digraph is transformed into the system through replacing bulge to the testimonials.

Step 8: - the interpretative self-interaction matrixes gained in step 7 is needed to check more for the consistency and inconsistency of the variables.

\section{Result and Discussion}

4.1. Developing Relationship among variables

The system designed based on the opinions of the experts and developing relative associations among each variable. Which is established based on the various organizations, procedures like brainstorming, insignificant method, nature of the environment, etc., and then it is used to develop the relative relationships between each barrier. To do this, 12 people from the plastic bottling company, 8 from small and intersperse, 5 from the Dire Dawa sanitation and the agency were accessed for data analysis during the case study period. 
Table 1:- Relationship matrixes for all barriers

\begin{tabular}{|c|c|c|c|c|c|c|c|c|c|c|c|c|c|}
\hline$s / n$ & Variables & Xiii & Xii & $\mathbf{X i}$ & $\mathbf{X}$ & ix & Viii & vii & vi & V & iv & iii & ii \\
\hline 1 & Government regulation & A & V & V & V & $X$ & V & A & X & V & A & A & $\mathrm{O}$ \\
\hline 2 & Lack of information about RL & $\mathrm{V}$ & V & A & $\mathrm{A}$ & A & $\mathrm{V}$ & V & $\mathrm{O}$ & $\mathrm{O}$ & $\mathrm{X}$ & $\mathrm{O}$ & - \\
\hline 3 & Attitude of the people & $\mathrm{V}$ & V & $\mathrm{X}$ & A & $\mathrm{V}$ & A & A & $X$ & $\mathrm{O}$ & A & - & \\
\hline 4 & Problems with product quality & $\mathrm{X}$ & V & $\mathrm{X}$ & A & A & A & A & A & $\mathrm{V}$ & - & & \\
\hline 5 & Company policy & $\mathrm{V}$ & $\mathrm{X}$ & $\mathrm{V}$ & A & $\mathrm{X}$ & $\mathrm{O}$ & $\mathrm{O}$ & $\mathrm{O}$ & - & & & \\
\hline 6 & Struggle for improvement of RL & $\mathrm{V}$ & $\mathrm{V}$ & $\mathrm{V}$ & A & $\mathrm{V}$ & $\mathrm{O}$ & A & - & & & & \\
\hline 7 & Absence of suitable routine environment & $\mathrm{X}$ & $\mathrm{O}$ & A & $\mathrm{V}$ & A & $X$ & - & & & & & \\
\hline 8 & Shortage of exercise associated with RL & $\mathrm{V}$ & $\mathrm{V}$ & A & $\mathrm{V}$ & $\mathrm{V}$ & - & & & & & & \\
\hline 9 & $\begin{array}{l}\text { Absence of higher management } \\
\text { commitment }\end{array}$ & A & A & A & $\mathrm{V}$ & - & & & & & & & \\
\hline 10 & $\begin{array}{l}\text { Reluctance to support for the distributer, } \\
\text { retailer and dealers }\end{array}$ & $\mathrm{V}$ & $\mathrm{O}$ & $\mathrm{V}$ & - & & & & & & & & \\
\hline 11 & $\begin{array}{l}\text { Lack of awareness and education about } \\
\text { RL }\end{array}$ & $\mathrm{V}$ & A & - & & & & & & & & & \\
\hline 12 & Absence of tactical scheduling & $\mathrm{V}$ & - & & & & & & & & & & \\
\hline 13 & Financial constraint & - & & & & & & & & & & & \\
\hline
\end{tabular}

Based on Table 1, relationship matrixes between each variable, the presence of the relative barriers such as [j and i] which shows the related way of the relationship of the barriers were developed. In the case study, the study used 4 symbols for more demonstration which are defined as follows:-

$>$ Symbol A: - Indicates Barriers i alleviated Barriers j

$>$ Symbol V: - Indicates Barriers i help to alleviate of barriers $\mathrm{j}$

$>$ Symbol X; - Indicates as both barriers assisted one to the other to achieve

$>$ Symbol O; - Bothe $\mathrm{i}$ and $\mathrm{j}$ are unrelated according to review of (Kannan 2009).

\subsection{Relationship matrix}

The system is further transferred to the duality matrix, which is called as the original relationship matrix by replacing the symbols $\mathrm{O}, \mathrm{X}, \mathrm{A}$, and $\mathrm{V}$ by 0 and 1 and 0 based on the circumstance. Maybe the procedure of the replacement of the symbol is shown as follows:-

1. If symbol $\mathrm{V}$ is used in the relationship matrix will become 1 at the entrance of $[\mathrm{i}, \mathrm{j}]$ and the entrance of $[\mathrm{j}, \mathrm{i}]$ will become 0 .

2. Again, if it is $[i, j]$ is $A$, then it will be 0 , including $[j, i]$ will be 1 .

3. Again for the entrance of $[i, j]$ is $X$, in both cases $[i, j]$ and $[j, i]$ will be 1 .

4. Lastly, if the entrance of $[i, j]$ is $O$, then $[j i$,$] will be also 0$.

All the above variables relationship procedures would be implemented as shown in Table 2 .

Table 2. Primary iteration of relationship of the variables

\begin{tabular}{|c|c|c|c|c|c|c|c|c|c|c|c|c|c|c|c|}
\hline $\mathrm{s} / \mathrm{n}$ & Barriers & I & ii & Iii & Iv & V & $\mathrm{Vi}$ & vii & viii & ix & $\mathrm{X}$ & $\mathrm{Xi}$ & xii & xiii & $\begin{array}{l}\text { Driver } \\
\text { power }\end{array}$ \\
\hline 1 & Government ruling & 0 & 1 & 1 & 0 & 0 & 1 & 0 & 1 & 0 & 1 & 1 & 0 & 0 & 6 \\
\hline 2 & $\begin{array}{l}\text { Lack of information about } \\
\text { RL }\end{array}$ & 0 & 1 & 1 & 0 & 1 & 1 & 1 & 0 & 0 & 1 & 0 & 0 & 0 & 6 \\
\hline 3 & Attitude of the people & 0 & 1 & 1 & 1 & 1 & 0 & 1 & 1 & 1 & 1 & 1 & 0 & 0 & 9 \\
\hline 4 & $\begin{array}{l}\text { Problems with product } \\
\text { quality }\end{array}$ & 0 & 1 & 1 & 1 & 1 & 0 & 1 & 0 & 0 & 0 & 1 & 1 & 1 & 8 \\
\hline 5 & Company policy & 1 & 1 & 1 & 1 & 1 & 1 & 1 & 1 & 0 & 1 & 0 & 0 & 0 & 9 \\
\hline 6 & $\begin{array}{l}\text { Struggle to change activities } \\
\text { related to RL }\end{array}$ & 1 & 1 & 0 & 0 & 0 & 1 & 1 & 1 & 0 & 1 & 0 & 0 & 0 & 6 \\
\hline 7 & $\begin{array}{l}\text { Absence of suitable routine } \\
\text { environment }\end{array}$ & 0 & 1 & 1 & 1 & 1 & 1 & 1 & 1 & 1 & 0 & 0 & 1 & 1 & 10 \\
\hline 8 & $\begin{array}{l}\text { Shortage of exercise } \\
\text { associated with RL }\end{array}$ & 0 & 1 & 1 & 0 & 1 & 0 & 1 & 1 & 0 & 1 & 0 & 0 & 0 & 6 \\
\hline 9 & $\begin{array}{l}\text { Absence of higher } \\
\text { management commitment }\end{array}$ & 0 & 0 & 0 & 0 & 0 & 0 & 0 & 0 & 1 & 0 & 0 & 0 & 1 & 2 \\
\hline 10 & $\begin{array}{l}\text { Reluctance of the support of } \\
\text { distributer, retailer and } \\
\text { dealers }\end{array}$ & 1 & 0 & 0 & 1 & 0 & 0 & 1 & 0 & 1 & 1 & 0 & 1 & 0 & 6 \\
\hline
\end{tabular}




\begin{tabular}{|c|c|c|c|c|c|c|c|c|c|c|c|c|c|c|c|}
\hline $\mathrm{s} / \mathrm{n}$ & Barriers & I & ii & Iii & Iv & V & $\mathrm{Vi}$ & vii & viii & ix & $\mathrm{x}$ & $\mathrm{Xi}$ & xii & xiii & $\begin{array}{l}\text { Driver } \\
\text { power }\end{array}$ \\
\hline 11 & $\begin{array}{l}\text { Lack of awareness and } \\
\text { education about RL }\end{array}$ & 1 & 1 & 0 & 0 & 1 & 1 & 1 & 1 & 0 & 1 & 1 & 1 & 0 & 9 \\
\hline 12 & $\begin{array}{l}\text { Absence of tactical } \\
\text { scheduling }\end{array}$ & 0 & 0 & 0 & 0 & 1 & 0 & 1 & 1 & 1 & 0 & 1 & 1 & 1 & 7 \\
\hline 13 & Financial constraint & 0 & 1 & 1 & 0 & 1 & 1 & 0 & 1 & 0 & 1 & 1 & 0 & 1 & 8 \\
\hline & Dependence power & 7 & 9 & 8 & 6 & 5 & 10 & 10 & 9 & 5 & 9 & 4 & 5 & 4 & \\
\hline
\end{tabular}

Based on Table 2 initial or the primary relationship matrix obtained in step 3 is transformed to the final step of the relationship through checking their transferring procedures. Based on contextual relationship in transferring assumption in interpretive structural' matrix, If a component ' $A$ ' is associated with component ' $B$ ', and ' $B$ ' is associated with ' $\mathrm{C}$,' that means ' $\mathrm{A}$ ' is directly associated with ' $\mathrm{C}$ '.

\subsection{Barriers levels}

According to the Stock (2016) reviews, the predecessor set and joint set can be found at the end of the relationship matrix. In this assumption, the relationship between the variables for certain particular variables consists of the variable itself and to each other. In the case of relationship and predecessor set joint at the higher rate in the interpretive structural model will be taken to the top level in the system hierarchy.

Table 3. Relationship of the variables

\begin{tabular}{c|llll}
\hline VARIBLES & \multicolumn{1}{l}{ RELATIONSHIP SET } & PREDECESSOR SET & JOINT & STAGE \\
\hline I & $1,3,4,6,7,9,12,13$ & $1,5,6,8,9,10,11$, & $1,6,9$ \\
II & $2,3,5,6,7,10$ & $2,3,5,6,8,11,12,13$ & $2,3,5,6$ \\
III & $2,3,4,5,7,8,9,10,11,12$ & $1,2,3,5,8,9,12,13$ & $2,3,5,8,9,12$ \\
IV & $4,6,7,8,9$ & $1,3,4,5,10,12$ & 4 & $2,3,5$ \\
V & $1,2,3,4,5,6,7,8,10$ & $2,3,5,11,13$ & I \\
VI & $1,2,6,7,8,10$ & $1,2,4,5,6,8,9,11,12,13$ & $1,2,6,8$ & \\
VII & 7 & $1,2,3,4,5,6,7,9,10,11$ & 7 \\
VIII & $1,2,3,6,8,10$ & $3,4,5,6,8,9,11,12,13$ & $3,6,8$ & $1,3,9$ \\
IX & $1,2,3,6,7,8,9,11,12,13$, & $1,3,4,9,10$ & 10,12 & \\
X & $1,4,7,9,10,12$ & $2,3,5,6,8,10,11,12,13$ & 11 \\
XI & $1,2,5,6,7,8,10,11,12$ & $9,11,13$ & 10,12 & 13 \\
XII & $2,3,4,6,8,10,12,13$ & $1,9,10,11,12$ & \\
XIII & $2,3,5,6,8,10,11,13$ & $1,9,12,13$ &
\end{tabular}

As shown in the Table 3, the absence of a suitable routine environment (variable 7) will be at the top of step 1. This means, it is the variable placed on the first stage position of the system. The repetition is sustained all levels of each barrier in the system. Therefore, the absence of a suitable routine environment in these mechanisms helps in building the final graph of the models in ISM model in this structural model system.

The same iteration for other variables has been made and final result came up with Table 4. Refer the iteration of the other variables under the Appendix.

Table 4: Final iteration Relationship of the variables

\begin{tabular}{|c|l|l|l|l|}
\hline Varibles & Relationship Set & Predecessor Set & Joint & stage \\
\hline ix & 9,11 & 9, & 9 & VIII \\
\hline xi & 11 & 9,11 & 11 & VII \\
\hline
\end{tabular}

As shown in Figure 2 of ISM model, the absence of higher management commitment in the case of reverse logistic system performs is somehow important variable. This indicates the model shows a lack of awareness about the term reverse logistic systems is great value in the case town. RL issues like company policy, financial constraint and lack of strategic planning is at the lowest stage in the system hierarchy. This is suggesting that it has greater energetic influence on the solid waste management system. 


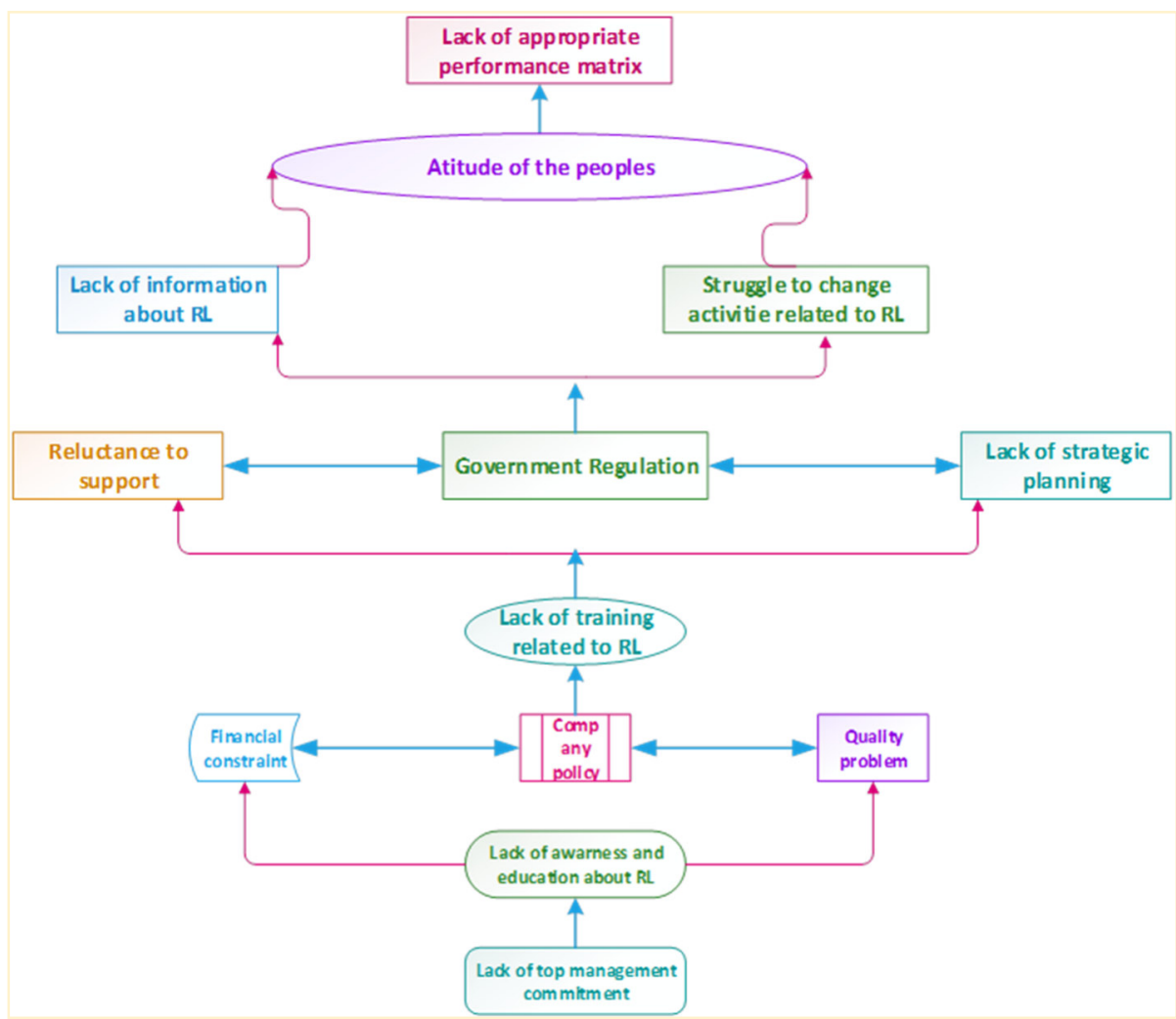

Fig 2: Reverse logistic structural model [from MICMAC Analysis]

To develop an effective strategy, the top management must take part in each activity. Especially in creating awareness about the reverse logistic system, the commitment of the higher institute plays a great role. But based on some studies result, lack of awareness about reverse logistic was found to be the most influential barrier that was affecting the implementation system (Herbert, 2017). In this study finding of adaptation of the interpretive structural modeling methodology, top management is the most influential barrier that is affecting reverse logistic system in the Dire Dawa city. 

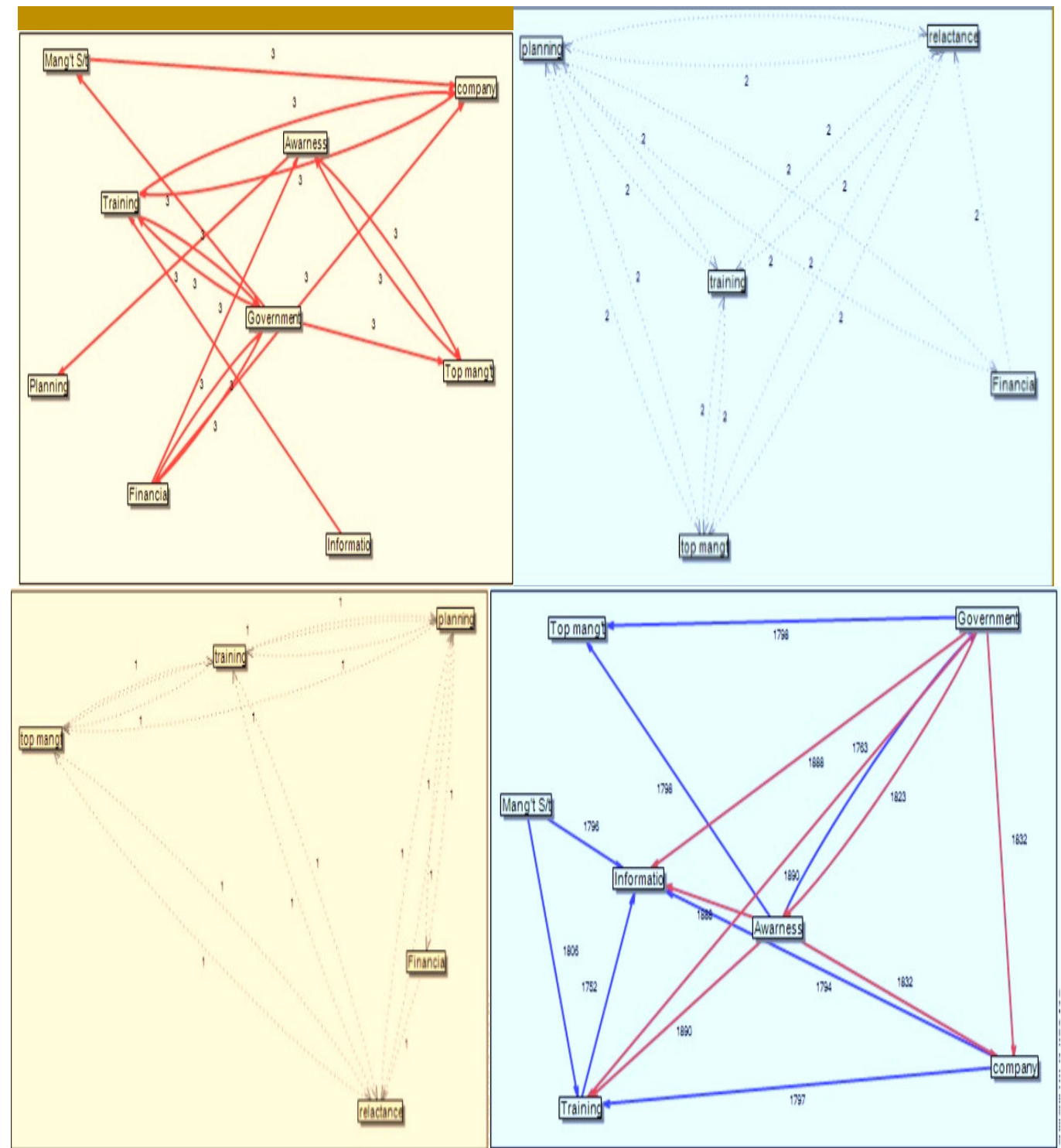

Fig 3: Performance of the variable across each other's based on the reachability matrix

As indicated in Figure 3 that the performance of the variables across each other in reachability matrix is shown. It indicates the strength of each variable relationship against each other.

Table 5: Influential and Dependence performance of the variables
\begin{tabular}{|l|l|l|}
\hline No. of iteration & Influential variable & Dependence variables \\
\hline 1 & $91 \%$ & $98 \%$ \\
\hline 2 & $100 \%$ & $98 \%$ \\
\hline
\end{tabular}

As the result indicated in Table 5 from MICMAC, the potential influential variables between the Barriers that affecting the implementation of reverse logistics in the dire Dawa city imply that $91 \%$ first iteration and $100 \%$ influence each other in the second iteration. But the dependence variables in both iterations are similar which means $98 \%$ iteration. From the Interpretive structural model, it is easy to make realistic decisions and helps to implement a reverse logistics system in the case study. So, the interpretive structural model helps to conclusive through making precedence to an effective strategy for struggling variables in the case study.

\section{Conclusion and Recommendation}

Dire Dewa is found that it is preferable and compatible with plastic bottles reverse logistic system to export into China. Due to a lack of awareness and top management commitments, Dire Dawa city is not used this golden advantage of compatible reverse logistics systems. Due to environmental conditions and community culture changes in using plastic bottle, the consumption of plastic bottles beverage is increasing from time to time. To satisfy these demands, around 9 water bottling plastic bottles produce their average production capacity of $\mathbf{4 0 , 0 0 0}$ to 75,000 production /day. Of this, researcher analyze that around 3,585, 893.5 plastic bottles/week has been read for recycling. To carry out this, the city has obtained an economic advantage of around $\mathbf{\$ 1 6 0 , 2 9 7 . 8 2 4}$ monthly. To 
attain this economic advantage, top management plays a great role followed by the creation of awareness regarding this area as interpretive structural model (ISM) result shows. The model is solved through MICMAC software.

This research forward suggestions and recommendations which can help to solve the process, problems and ensure effective recovery system, in order to achieve economic advantage and protect the environment from the adverse effects caused by solid waste thrown here and there in the city. So, the researcher identified the problems and forwarded possible interpretations for difficulties suffered as follows:-

$>$ In maximize recovery system in Dire Dawa city, Top management should play a great role, followed by awareness creation, financial constraint, company policy and quality of the product, as discussed in the model above.

$>$ Municipal solid management should be supported by the participation of people in separating solid waste from other organic materials at the source itself.

$>$ The community should be trained at Kebele level about the usage and proper disposal system.

$>$ Government bodies should be work of organizing and supporting informal sectors which work on recovering system.

$>$ Policies should be developed that encourage and promote informal sectors by taking into consideration the economic benefits gained from recovering system, in terms of the contributions towards pollution control, and conservation of natural resources.

Private sectors who are willing to plant recovering system should be encouraged by lowering tax requirement, providing affordable space for recycling plant and marketing, allowing tax free imports of machinery and so on.

\section{Reference}

1. Khan S, Faroqi K. Prioritizing municipal solid waste management factors in India using a fuzzy analytic hierarchy process. Int. J.Environ. Wast.2017:4:423-440.

2. Chatha K. Butt I. Themes of study in manufacturing strategy literature. Int. J. Mang. Scie. 2015:4:604-698.

3. Chakraborty S, Das K, and Satapathy S. Recycling in plastic industries in India: An analysis of its barriers through fuzzy-approach. Int. J. Adv. 2018; 3:290-301.

4. Chatha K. Butt I. Themes of study in manufacturing strategy literature. Int. J. Mang. Scie. 2015:4:604-698.

5. Henry K, Yongsheng Z, Dong Jun. Municipal solid waste management challenges in developing countries-a Kenyan case study. Int. J. Waste mang. 2016: 26:1:92-100.

6. Govindan K, Shaligram P, Sasikumar P. A hybrid approach using ISM and fuzzy TOPSIS for the selection of reverse logistics provider. Res, Conserv. Recyc. 2016:54:28-36.

7. Kokkinaki A. From e-trash to e-treasure: how value can be created by the new e-business models for reverse logistics. Int. J. adv. 2000:32:2017.

8. Krumwiede D. Chwen S. A model for reverse logistics entry by third-party providers. Int. J. Eng. Mang. Scie. 2018:5:325-333.

9. Mandal A. Deshmukh S Vendor selection using interpretive structural modeling (ISM). Int. J. Mang. Scie. 2015:6:52-59.

10. Mandal A. Deshmukh S.2016. Vendor selection using interpretive structural modeling (ISM). Int. J. Prod. Mang. Scie. 2016:14, 52-59.

11. Ravi V, Ravi S. Analysis of interactions among the barriers of reverse logistics. Techno. adv. Sci. 2015:8:1011-1029.

12. Lambert D, Sabastian M, Garcia D, Keely L. the role of logistics managers in the cross - functional implementation of supply chain management. Res.gate.2016:4:579-485.J. Business. Log.2018:1:113-132.

13. Clive L. Roberts G, Watkin D, and Chukwunonye E. Seasonal variation and municipal solid waste composition issues for development of new waste management strategies. Int. J. adv. 2016:32:2017.

14. Fleischmann, M, Krikke H, Dekker R. and Flapper S. A characterization of logistics networks for product recovery. Omega 2018, 28, 653-666.

15. Agamuthu M. Khidzir S. Hamid M. Drivers of sustainable waste management in Asia, Waste Manage \& Research. sciec. Direct.2018: 686-6930

16. Zhang H, and Wen G, The Consumption and Recycling Collection System of PET Bottles: A Case Study of Beijing, China, Waste Manage. Int.J.adv. scie 2014: 34, 2014, 987-998.

17. Pohlen, T, Farris, M. Reverse logistics in plastics recycling. Inter. J. Phys. Distrib. Logist. Manag. 1992, 22 , 35-47.

18. Centenera J, Hasan M. Sustainable product-service system. Int. Bus. Res. 7, (2014), 62-71.

19. Anantanatorn A, Yossomsakdi S, Wijaya A, Rochma S. Public Service Management in Local Government, Thailand Int. J. Appl. Soc. 2015;5:5-15

20. Chowdhury M. Paul H, Das, A. The impact of top management commitment on total quality management practice: An exploratory study in the Thai government industry. Glob. J. Flex. Syst. Manag. 2017, 8, 17-29

21. Vajarodaya P, Poboon C, Chompunth C. The Solid Waste Management of Local Altority, Rayong Province. $J$. 
Environ. Manag. 2015; 10:71-89.

22. Mandal A, Deshmukh G, Vendor selection using interpretive structural modeling (ISM), Int. J. Oper. Prod. Manage. 14 (6) (2017) 52-59.

23. Yukalang N. Barriers to Effective Municipal Solid Waste Management in a Rapidly Urbanizing Area in Thailand. Int. J. Environ. Res. Public Health. 2017 Sep; 14(9): 1013

24. Stock J. Thomas S. Herbert S. Many happy (product) returns. Int.J.adv. scie.2016:2; 16-17.

\begin{tabular}{|c|c|c|c|c|}
\hline VARIBLES & RELATIOSNSHIP SET & PREDECESSOR SET & JOINT & STAGE \\
\hline I & $1,6,4,3,9,12,13$ & $1,5,6,8,9,10,11$ & $1,6,9$ & \\
\hline II & $2,3,6,5,10$ & $2,3,5,6,8,11,12,13$ & $2,3,5,6$ & \\
\hline III & $2,5,3,4,8,9,10,11,12$ & $1,2,3,5,8,9,12,13$ & $2,3,5,8,9,12$ & II \\
\hline IV & $4,6,8,9$ & $1,3,4,5,10,12$ & 4 & \\
\hline $\mathbf{V}$ & $1,2,3,4,5,6,8,10$ & $2,3,5,11,13$ & $2,3,5$ & \\
\hline VI & $1,2,6,8,10$ & $1,2,4,5,6,8,9,11,12,13$ & $1,2,6,8$ & \\
\hline VIII & $1,2,3,6,8,10$ & $3,4,5,6,8,9,11,12,13$ & $3,6,8$ & \\
\hline IX & $1,2,3,6,8,9,11,12,13$ & $1,3,4,9,10$ & $1,3,9$ & \\
\hline $\mathbf{X}$ & $1,4,9,10,12$ & $2,3,5,6,8,10,11,12,13$ & 10,12 & \\
\hline XI & $1,, 2,5,6,8,10,11,12$ & $9,11,13$ & 11 & \\
\hline XII & $2,3,4,6,8,10,12,13$ & $1,9,10,11,12$ & 10,12 & \\
\hline XIII & $2,3,5,6,8,10,11,13$ & $1,9,12,13$ & 13 & \\
\hline
\end{tabular}

Table S2. Relationship of the variables

\begin{tabular}{|c|c|c|c|c|}
\hline VARIBLES & RELATIONSHIP SET & PREDECESSOR SET & JOINT & STAGE \\
\hline I & $4,6,1,9,12,13$ & $1,5,6,8,9,10,11$ & $1,6,9$ & \\
\hline II & $2,6,5,10$ & $2,5,6,8,11,12,13$ & $2,3,5,6$ & III \\
\hline IV & $4,6,8,9$ & $1,4,5,10,12$ & 4 & \\
\hline $\mathbf{V}$ & $1,2,4,5,6,8,10$ & $2,5,11,13$ & 2,5 & \\
\hline VI & $1,2,6,8,10$ & $1,2,4,5,6,8,9,11,12,13$ & $1,2,6,8$ & III \\
\hline VIII & $1,2,6,8,10$ & $4,5,6,8,9,11,12,13$ & 6,8 & \\
\hline IX & $1,2,6,8,9,11,12,13$, & $1,4,9,10$ & 1,9 & \\
\hline $\mathbf{X}$ & $1,4,9,10,12$ & $2,5,6,8,10,11,12,13$ & 10,12 & \\
\hline $\mathbf{X I}$ & $1,, 2,5,6,8,10,11,12$ & $9,11,13$ & 11 & \\
\hline XII & $2,4,6,8,10,12,13$ & $1,9,10,11,12$ & 10,12 & \\
\hline XIII & $2,5,6,8,10,11,13$ & $1,9,12,13$ & 13 & \\
\hline
\end{tabular}

Table S3. Relationship of the variables

\begin{tabular}{|c|c|c|c|c|}
\hline VARIBLES & RELATIONSHIP SET & PREDECESSOR SET & JOINT & STAGE \\
\hline I & $9,1,4,12,13$ & $1,5,8,9,10,11$ & 1,9 & IV \\
\hline IV & $4,8,9$ & $1,4,5,10,12$ & 4 & \\
\hline $\mathbf{V}$ & $1,4,5,8,10$ & $5,11,13$ & 5 & \\
\hline VIII & $1,8,10$ & $4,5,8,9,11,12,13$ & 8 & \\
\hline IX & $1,8,9,11,12,13$ & $1,4,9,10$ & 1,9 & \\
\hline $\mathbf{X}$ & $1,4,9,10,12$ & $5,8,10,11,12,13$ & 10,12 & IV \\
\hline $\mathbf{X I}$ & $1,5,8,10,11,12$ & $9,11,13$ & 11 & \\
\hline XII & $4,8,10,12,13$ & $1,9,10,11,12$ & 10,12 & $1 \mathrm{~V}$ \\
\hline XIII & $5,8,10,11,13$ & $1,9,12,13$ & 13 & \\
\hline
\end{tabular}


Table S4. Relationship of the variables

\begin{tabular}{r|llll}
\hline VARIBLES & RELATIONSHIP SET & PREDECESSOR SET & JOINT & STAGE \\
\hline IV & $8,4,9$ & 4,5, & 4 & \\
V & $5,4,8$ & $5,11,13$ & 5 & \\
VIII & 0,8 & $4,5,8,9,11,13$ & 8 & V \\
IX & $9,8,11,13$ & 4,9, & 9 & \\
XI & $5,8,11$ & $9,11,13$ & 11 & \\
XIII & $5,8,11,13$ & 9,13 & 13 &
\end{tabular}

Table S5. Relationship of the variables

\begin{tabular}{|c|c|c|c|c|}
\hline VARIBLES & RELATIONSHIP SET & PREDECESSOR SET & JOINT & STAGE \\
\hline IV & 9,4 & 4,5 & 4 & VI \\
\hline V & 5,4 & $5,11,13$ & 5 & VI \\
\hline IX & $11,9,13$ & 4,9 & 9 & \\
\hline XI & 11,5 & $9,11,13$ & 11 & \\
\hline XIII & 11,5 & 9,11 & 11 & VI \\
\hline
\end{tabular}

